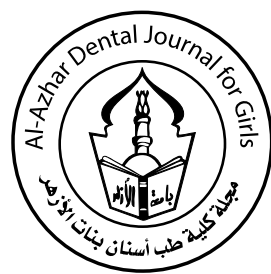

\title{
The Effect of Different Surface Treatments on Light Transmittance and Fracture Resistance of Fiber Posts
}

\author{
Walaa El Mekkawi (1) and Suad Mohammed ${ }^{(1)}$
}

Codex : 31/1807

azhardentj@azhar.edu.eg

http://adjg.journals.ekb.eg

\section{KEYWORDS}

Fracture,

Resistance,

Fiber post

\begin{abstract}
Objective: The objective of this study was to evaluate the light transmittance and fracture resistance of fiber posts following application of various surface treatments. Materials and Methods: Fiber post specimens (GLASSIX+ Pluse. Nordin, redsize, swiss) were tested $(n=7)$. The fiber posts were divided into four groups according to the application of surface treatments: Group 1: No surface treatment; Group 2: Irradiated with erbium: Yttrium-aluminum-garnet laser; Group 3: Airborne-particle abraded with $110 \mathrm{pm} \mathrm{Al} \mathrm{O}_{3}$; Group 4: Etched with hydrofluoric acid (HF) + silane application. After measuring light transmittance these fiber posts are cemented in endodontically treated teeth by resin cement to evaluate fracture resistance by universal testing machine. Results: One-way ANOVA revealed the highest mean value in light transmittance was recorded in control group, whereas the lowest mean value was recorded after Etched with hydrofluoric acid. ANOVA test revealed that the difference between treatments was statistically significant ( $\mathrm{p}=0.029$ ). Tukey's post hoc test revealed no significant difference between control group and LASER. Moreover, there was no significant difference between Laser group and Sandblasting group. Etched group with hydrofluoric acid was significantly lower than control group and LASER group. The highest mean fracture resistance value was recorded after Etching with hydrofluoric acid, whereas the lowest mean value was recorded in Sandblasting group. ANOVA test revealed that the difference between treatments was not statistically significant $(\mathrm{p}=0.996)$. Conclusion: Application of surface treatments might negatively affect the light transmission property of fiber posts.
\end{abstract}

\section{INTRODUCTION}

The restoration of endodontically treated teeth with all-ceramic units in high demand esthetic zone, led to the introduction of esthetic posts such as glass fiber reinforced composite resin posts (FRC), and yttrium 
stabilized zirconia-based ceramic posts which are

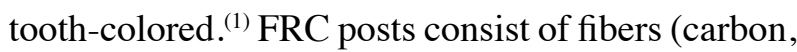
quartz, silica, zirconia, or glass) in a resin matrix with a silane coupling agent binding the fibers and matrix together. ${ }^{(2)}$ In addition, the major advantage of the FRC posts is the elastic modulus, which is equal to that of dentin, as well as high durability which may lead to a better distribution of the occlusal loads along the root.$^{(3)}$

The use of resin-based luting agents indicated for the retention of fiber post avoid friction between root canal walls and passively retained posts. ${ }^{(4)}$ In addition, the retention of the post is one of the critical factors that could influence the quality of the restoration. Therefore, for adequate clinical function and for reliable bond formation at the root-post core interfaces, the use of dual-cured or self-curing resin-based cements has been recommended (5) To convert monomer into polymer in resin-based material, resin cements should be polymerized properly. ${ }^{(6)}$

Moreover, the higher degree of monomer conversion is associated with improvements in the mechanical properties of resin-based materials. ${ }^{(7)}$ Besides, the posts should transmit light to reach an adequate degree of cure at depth to permit curing of the cement throughout the apical region of the tooth. ${ }^{(8)}$

Therefore, translucent fiber posts are used to overcome the problem of lack of curing in deep regions of root. ${ }^{(9)}$ use of fiber post and core systems has been extensively investigated and supported by clinical $^{(10)}$ and laboratory studies. ${ }^{(11)}$

In order to allow for optimal retention and favorable stress distribution inside the root canal ${ }^{(12)}$ resin based luting agents are indicated for fiber post cementation ${ }^{(13)}$. Light curing resins are not recommended for fiber post cementation because of inadequate depth of cure in the apical portions of the root, even if translucent posts are used ${ }^{(14)}$.
Therefore, dual-cured and self-cured resin cements have been advised for fiber post cementation. Dual-cured resin cements have been widely used by the clinicians and were investigated in a number of clinical studies. These cements are expected to adequately polymerize in areas which cannot be entirely reached by light as well as in complete absence of light. Nevertheless, it was reported that in the absence of light some dual-cured cements may not reach an adequate degree of conversion. ${ }^{(15)}$

Therefore, light curing was recommended for dual-cured resin cements. Put in our consideration the depth of post space preparations, translucent fiber posts were introduced in order to facilitate light curing. Adequate curing is considered to be especially important in the apical portions of the root canals which have presented impaired adhesion in the studies that deal with differences in adhesion along the post space. ${ }^{(16)}$

Recent investigations pointed out that the amount of transmitted light differs between different fiber posts. Limited or no light transmission was recorded through some fiber posts that were claimed to be translucent by the manufacturers. ${ }^{(17)}$ A significant reduction of the quantity of transmitted light as the depth increased was also reported. ${ }^{(18)}$ Concern was raised regarding the ability of fiber posts to transmit light in the amount sufficient for polymerization of dual-cured resin cements in the apical portion of the post space.

The influence of fiber post translucency on the degree of conversion of dual-cured resin cement was investigated. ${ }^{(19)}$ The use of non-light transmitting carbon fiber post resulted in lower degree of conversion at medium depth of the post space in comparison to translucent fiber post. ${ }^{(20)}$ It may be assumed that the amount of light transmitted through the post affects dual-cured resin cement's coupling to root dentin and fiber post, as well as micromechanical properties of the cement it.

Mechanical and chemical surface treatments of fiber-reinforced posts have been tried to overcome 
post-cement adhesion failure Mechanical surface treatment such as sandblasting involves spraying a stream of aluminum oxide $\left(\mathrm{Al}_{2} \mathrm{O}_{3}\right)$ particles against the post surface under high pressure. It relies on particles abrasion with different particle sizes to remove superficial layer resulted in roughened surface that provides some degree of mechanical interlocking with the adhesive. ${ }^{(21)}$ Airborne-particles abrasion was reported to significantly improve retention of fiber posts cemented with dual-polymerizing resin cements. $^{(22)}$

Enhancing a mechanical interlock in post-cement interface was also attempted through exposure of the post's fibers with sandblasting followed by surface treatment with a silane coupling agent. However, sandblasting with $\mathrm{Al}_{2} \mathrm{O}_{3}$ particles. ${ }^{(23)}$ or chemical etching with hydrofluoric acid ${ }^{(24)}$ may cause adverse effects on strength and fit of the fiber post when treatment is performed over a long period of time. ${ }^{(25)}$

Recently, laser etching technology has become available as an alternative for improving roughness and bond strength of dental substrates and materials. ${ }^{(26)}$

The laser types employed in dentistry are argon laser, neodymium-doped yttrium aluminum garnet (Nd: YAG) laser, diode laser, erbium-doped YAG (Er: YAG), and erbium, chromium: Yttrium, scandium, gallium, garnet (Er, Cr: YSGG), and traditionally classified based on the active medium, for example, gas, liquid, solid state, or semiconductor diode. ${ }^{(27)}$ The newly introduced laser, Er, Cr: YSGG, is proposed for treatment of both soft and hard tissues with minimal thermal side-effects with a wavelength of $2.79 \mathrm{~mm}$ and represents strong absorption in water $(\mathrm{ma}=7000 / 7 \mathrm{~cm}){ }^{(28)}$

Previously, few reports have evaluated the light transmitting ability of posts. ${ }^{(29)}$ However, to date, no studies have examined the effect of surface treatment including laser treatment on light transmitting ability of fiber posts.
Therefore, the tested null hypothesis was the surface treatment of fiber posts adversely affect light transmitting ability of fiber posts. Based on these considerations, the aim of this study was to investigate the effect of different surface treatments on light transmission and adhesion of fiber posts.

\section{MATERIALS AND METHODS}

\section{Surface treatment of fiber posts:}

Prefabricated glass fiber posts (GLASSIX+ Pluse, Nordin, redsize, swiss) $(n=7 /$ per group $)$ were prepared to a length of $10 \mathrm{~mm}$ and a coronal diameter of $1.5 \mathrm{~mm}$.

The surface treatments were confined to a $8 \mathrm{~mm}$ wide parallel band measured from the coronal end. In Group 1, no surface treatment was performed, and it served as control. In Group 2, the posts were irradiated with erbium, chromium: Yttrium, aluminum, garnet laser. The bonding surfaces of the post specimens were irradiated with an Er-Cr: YSGG laser system (Waterlase MD, Biolase Technology Inc., San Clemente, CA, USA) operating at a wavelength of $2780 \mathrm{~nm}$ and having pulse duration of 140-200 $\mathrm{ms}$ with a repetition rate of $10 \mathrm{~Hz}$. The power output was set at $1.5 \mathrm{~W}$. In addition, the average exposure time was set at $10 \mathrm{~s}$, and the distance of application was $10 \mathrm{~mm}$. Moreover, air and water spray from the hand piece was adjusted to a level of $85 \%$ air and $85 \%$ water during the lasing of the specimens.

In Group 3, the posts were sandblasted with 110 um diameter aluminum oxide particles (Rocatec Pre; $3 \mathrm{M}$ Espe) at a distance of $1 \mathrm{~cm}$ at $2.8 \mathrm{bar}$ for 5 s. In Group 4, posts were etched with $9.6 \% \mathrm{HF}$ for $60 \mathrm{~s}$ and rinsed with deionized water for $2 \mathrm{~min}$. Then silanization (EspeSil) was performed for $60 \mathrm{~s}$.

\section{Measurement of light transmission:}

Light transmission was measured using a transmission optical light microscope coupled with a spectrometer (Perkin-Elmer FT-IR System 2000 Model, CA, USA). The measurements were 
performed from the bottom end of each post. The light source was transmitted through the cut end and measured the intensity percentage of light (compared with the reference of 100\%) for each post. Values are given as the percentage of incident light measured at the opposite length of the post.

Measurement of fracture resistance:

Twenty eight sound human decoronated and endodontically treated teeth were embedded in epoxy resin blocks, then divided into four groups ( $\mathrm{n}$ $=7$ ) according to surface treatment of fiber post. Group 1 (control): roots restored with glass fiber post without surface treatment. Group 2: roots restored with glass fiber Irradiated with erbium: Yttrium-aluminum-garnet laser; Group 3: roots restored with glass fiber abraded with Airborne-particle 110 urn $\mathrm{A}_{2} \mathrm{O}_{3}$; Group 4: roots restored with glass fiber post Etched with hydrofluoric acid $(\mathrm{HF})+$ silane application. The specimens were individually mounted at $45^{\circ}$ angles and statically compressed until fracture at a $0.5 \mathrm{~mm} / \mathrm{min}$ crosshead speed with a $5 \mathrm{kN}$ load cell. The type of failure was assessed using a magnification lens.

Data were statistically analyzed.

\section{Statistical analysis}

Values were presented as mean and standard deviation (SD) values. One way analysis of variance
(ANOVA) test was used between surface treatment groups. This 'was followed by Tukey's post hoc test, when ANOVA yielded a significant difference. The significance level was set at $p<0.05$. Statistical analysis was performed with SPSS 18.0 (Statistical Package for Scientific Studies, SPSS, Inc., Chicago, IL, USA) for Windows.

\section{RESULTS}

\section{I- Light transmission}

The highest mean value was recorded in control, whereas the lowest mean value was recorded after Etched with hydrofluoric acid. ANOVA test revealed that the difference between treatments was statistically significant ( $\mathrm{p}=0.029)$. Tukey's post hoc test revealed no significant difference between control and LASER. Moreover, there was no significant difference between Laser and Sandblasting. Etched with hydrofluoric acid was significantly lower than control and LASER (Table 1, Fig. 1).

\section{II- Fracture resistance}

The highest mean value was recorded after Etching with hydrofluoric acid, whereas the lowest mean value was recorded in Sandblasting group. ANOVA test revealed that the difference between treatments was not statistically significant $(\mathrm{p}=0$ 996), (Table 2, Fig.2)

Table (1) Light transmittance percentage values and standard deviation of all groups

\begin{tabular}{|c|c|c|c|c|c|c|}
\hline \multirow[t]{2}{*}{ Light transmission } & \multicolumn{4}{|c|}{ Fiber post after surface treatment } & \multirow[t]{2}{*}{$\mathbf{F}$} & \multirow[t]{2}{*}{$\mathrm{P}$} \\
\hline & Control & LASER & Sand blasted & $\begin{array}{c}\text { Etched with } \\
\text { hydrofluoric acid }\end{array}$ & & \\
\hline Mean & $51.8^{\mathrm{a}}$ & $45.6^{\mathrm{a}, \mathrm{b}}$ & $38.1^{\mathrm{b}, \mathrm{c}}$ & $34.3^{\mathrm{c}}$ & \multirow[t]{2}{*}{3.57} & \multirow[t]{2}{*}{0.029} \\
\hline SD & 13.4 & 11.3 & 9.7 & 7.3 & & \\
\hline
\end{tabular}

Significance level $p<0.05, \quad *$ significant 
Table (2) Comparison of mean values of fracture resistance (Newton) after different surface treatments (ANOVA test)

\begin{tabular}{|c|c|c|c|c|c|c|}
\hline \multirow{2}{*}{$\begin{array}{l}\text { Fracture resistance } \\
\text { (Newton) }\end{array}$} & \multicolumn{4}{|c|}{ Fiber post after surface treatment } & \multirow[t]{2}{*}{$\mathbf{F}$} & \multirow[t]{2}{*}{$\mathrm{P}$} \\
\hline & Control & LASER & Sand blasted & $\begin{array}{c}\text { Etched with } \\
\text { hydrofluoric acid }\end{array}$ & & \\
\hline Mean & 543.7 & 542.6 & 541.6 & 549.4 & \multirow[t]{2}{*}{0.021} & \multirow[t]{2}{*}{$0.996^{\mathrm{ns}}$} \\
\hline SD & 69.3 & 48.6 & 7.81 & 53.7 & & \\
\hline
\end{tabular}

Significance level $p<0.05$

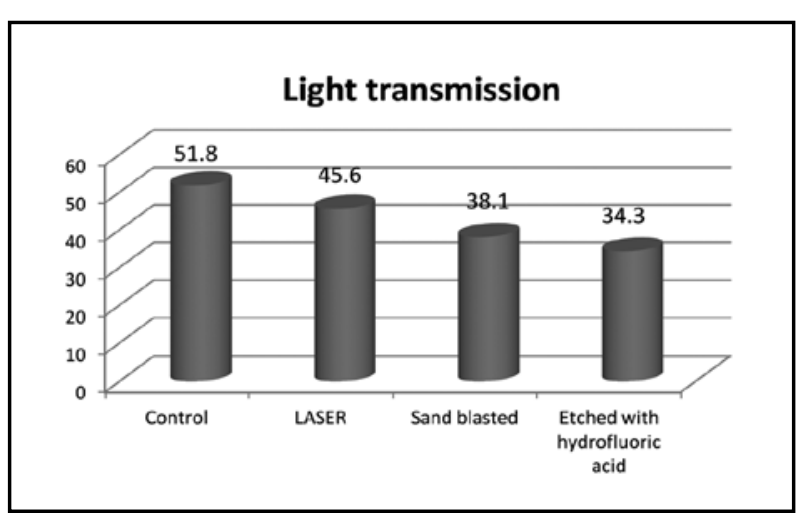

Fig. (1) Column chart showing mean values of light transmission after different surface treatments.

\section{DISCUSSION}

The null hypothesis was accepted as statistical analysis revealed differences between light transmittance percentage values of the posts following different surface treatments. It is known that the most important aspect in cementation of a fiber post in the root canal is the limitation of the cure rate as a function of the depth. ${ }^{(30)}$ In addition, residual unreacted monomers formed as a result of incomplete polymerization of the resin cement and adhesive. Moreover, these materials might leak through the apical root filling and could result in inflammatory, cytotoxic, and mutagenic reactions of periodontal tissue. ${ }^{(28,30)}$ Therefore, to perform adequate light polymerization, the posts should transmit light to permit curing of the cement throughout the apical region of the tooth. ${ }^{(31)}$

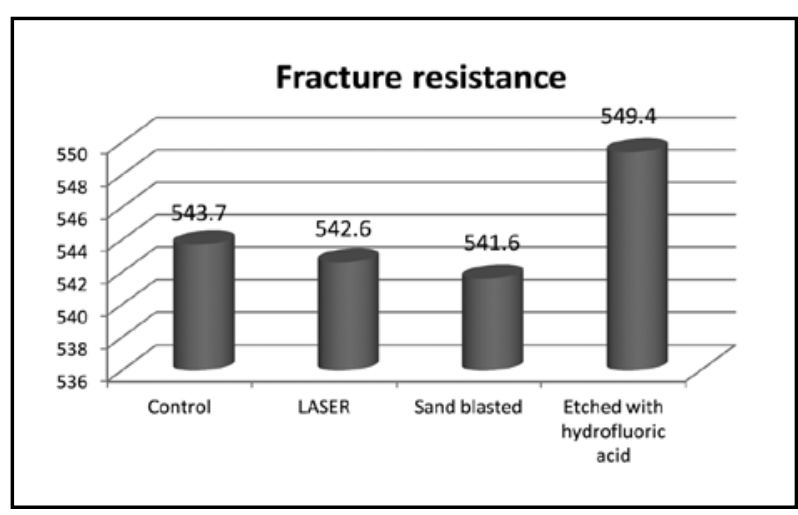

Fig. (2) Column chart showing mean values of fracture resistance (Newton) of fiber posts after different surface treatments

A previous study, investigated the light transmission through fiber posts and concluded that cementation of fiber post with no light transmitting ability using dual-cured resin cement resulted in lower percentage of continuity of resin cement-root dentin and resin cement-fiber post in comparison to cementation of light transmitting fiber post. ${ }^{(30)}$ They related this result with the presence of silica-zirconia fibers in the structure of fiber post used in that study. Similarly, the fiber posts used in this study was an esthetic post, composed of silica-zirconia fibers embedded in a resin matrix which might adversely influenced its light transmitting properties as the value of the control group was $54.22 \pm 3.09 \%$. In addition, a previous study evaluated light transmission behavior of translucent posts and found values lower than $40 \%$ of incident light. ${ }^{(28)}$ However, in this study, except the group treated 
with silane following HF application $(38.19 \pm 1.01)$, all the groups showed values higher than $40 \%$. This could be attributed to the differences between fiber contents and matrix structure of the posts.

In a previous study, the authors evaluated the effect of surface treatments on bond strength of resin core materials to three different types of fiber posts. (32) They indicated that surface treatment with HF was found to be effective method for improving the bonding of resin core materials to fiber posts except one post group and related this result with modification of the fiber post surfaces with HF. In addition, an enhancement of the surface roughness and a greater exposure of the fibers in comparison to the untreated post might have occurred. In addition, a previous study compared pretreatment methods $\left(\mathrm{HF}+\right.$ silane and $\mathrm{H}_{2} \mathrm{O}_{2}+$ silane $)$ of a fiber post on the push-out bond strength to root and showed that dissolution of resin matrix and glass fibers created a rough surface. ${ }^{(33)}$ Besides, in another study, ${ }^{(34)}$ it was stated that surface roughness might affect light scattering properties. Therefore, the lower light transmission values of the group treated with silane following HF application might be related with the surface roughness and thereby decrease in light transmission values. In addition, a previous study indicated that the light scattering intensity increases as the substrate roughness increases. ${ }^{(35)}$

The Er, Cr: YSGG laser chosen in this study was introduced with two different wavelengths to avoid the increase in the temperature of the dental pulp and absorption problems of carbon dioxide laser and the Nd: YAG laser. ${ }^{(36)}$ The lasers are also used to prepare dental materials for bonding on or into tooth surfaces. ${ }^{(37)}$ The specimens treated with laser demonstrated a higher percentage of light transmittance than HF treated and sandblasted groups. This could be attributed to lower deterioration of fiber post surfaces with laser treatment. Furthermore, a previous study evaluated the surface roughness and bond strength of glass fiber posts to a resin cement after various surface treatment and found fiber ruptures in the sandblasted posts when compared with Er: YAG laser irradiated specimens. Moreover, in this study, lower power setting was used $(1.5 \mathrm{~W})$ in accordance with a previous study, ${ }^{38}$ ' and the surfaces were irradiated with constant water and air cooling. Besides, application parameters of lasers such as energy, output power, pulse duration, and distance could affect surface characteristics and thereby light transmission values of posts. In addition, a study assimilated glass fiber to a multimode fiber optic. As they reported previously, the fiber acts like a core, the matrix like a cladding. In accordance with that study, the differences in the percentage of light transmission values among the posts could be possibly explained by the differences in refraction indices between the core and the cladding materials. ${ }^{(28)}$

Since the conversion of the present in vitro data to clinical outcomes constitutes great difficulty, clinical studies focusing on the effect of laser on dental materials' are needed. Therefore, further research is necessary to evaluate the optical properties of fiber posts in correlation with bond strength of posts to the resin cement in the root canal.

The matrix of modern FRC-post systems generally consists of synthetic resins or bisGMA polymers and only a few systems also contain PMMA chains of a high molecular weight $(>220 \mathrm{kDa})$. While fibers in FRC\% posts are meant to be the component with high tensile strength, the matrix should be considered to be the part which with stands compressive stresses, due to the high portion of macro- and microfillers in the resin matrix. Another function of matrix composites is the absorption of emerging stresses in the overall post system. Due to the different elastic moduli of glass/silica fibers and matrix composites stresses normally develop at the interface between the fibers and the matrix, and propagate along the surfaces of the fibers when the posts are loaded. Structural failures such as voids, cracks or micro bubbles, which might occur during the manufacturing process, will weaken the post ${ }^{(39)}$ Therefore it can be assumed that not only an increase of the fiber/matrix ratio alone, but also 
an increase of the total interface area will lead to a higher stiffness and a higher elastic modulus.

However, laboratory studies showed that it is not always desirable to raise the stiffness of FRC-posts to maximum values. The highest fracture strengths of restored teeth were obtained using posts with elastic moduli which were close to the elastic modulus of dentin. High values of elastic modulus often lead to unfavourable root fractures ${ }^{(40,41)}$. PMMAchains with a high molecular weight might plasticize the stiff highly cross-linked bisGMA matrix and reduce stress formation in the fiber-matrix interface during deflection ${ }^{(42)}$. This could be an explanation for the moderately good values of Para Post Fiber White, which contained the least amount of fibers. Embedding of fibers in a resin matrix is the reason for the improvement of the mechanical properties of all the post systems examined. However, the material and the manufacturing process of the fibers in these posts are obviously not identical. Commonly used posts usually contain eglass fibers (electric glass $/ \mathrm{e}$-modulus $=73 \mathrm{GPa}$ ) that consist of $\mathrm{SiO}_{2}, \mathrm{CaO}, \mathrm{B}_{2} \mathrm{O}, \mathrm{Al}_{2} \mathrm{O}$ and a few other oxides of alkali metals in its amorphous phase. R-Glass (86 GPa) and S-glass (high-strengthglass/87GPa) are also amorphous but differ in composition. ${ }^{42}$ The filament diameters of R- and Sglass are smaller which enhances the matrix ability to spread between the fibers and leads to an increase in inter laminar tightness. A similar quartzglass used in DT Light-Post and DT White-Post is made out of pure silica. Its elastic modulus does not differ much from the other types of glasses but its low coefficient of thermal expansion seems to benefit the structural integrity during thermal alteration $^{(434)}$ An other re-enforcing effect of fiber scan be created during the manufacturing process of posts. Pre-stressed fibers are soaked with resin and release after curing. This procedure causes compression of the glass fibers which are able to absorb tensile stresses while the post is exposed to flexural forces. Pre-treatment of fiber surfaces by sandblasting or silanization techniques are other methods essential in improving the strength of the fiber /matrix interface ${ }^{(45)}$ The present study aimed to show a correlation between mechanical properties and structural characteristics of selected FRC-post systems. This correlation could be detected between fiber/matrix ratio and flexural strength for fiber post. We didn't find investigations concide with our present study so we recommend further studies on the fracture resistance.

\section{CONCLUSIONS}

1. The surface treatments on fiber post might have negative effects on light transmitting properties.

2. The surface treatments on fiber post have no significant difference on fracture resistance.

\section{REFERENCES}

1. Egilmez F, Ergun G, Cekic-Nagas I, Vallittu PK, Lassila LV. Influence of cemen thickness on the bond strength of tooth-colored posts to root dentin after thermal cycling. Acta Odontol Scand 2013; 71: 175-82.

2. Cekic-Nagas I, Sukuroglu E, Canay S. Does the surface treatment affect the bond strength of various fibre-p ost systems to resin-core materials? J Dent 2011; 39: 171-9.

3. Goracci C, Grandini S, Bossu M, Bertelli E, Ferrari M. Laboratory assessment of the retentive potential of adhesive posts: A review. J Dent 2007; 35: 827-35.

4. Teixeira EC, Teixeira FB, Piasick JR, Thompson JY. An in vitro assessment of prefabricated fiber post systems. J Am Dent Assoc 2006; 137:1006-12.

5. Faria E Silva AL, Casselh DS, Ambrosano GM, Martins LR. Effect of the adhesive application mode and fiber post translucency on the push-out bond strength to dentin. J Endod 2007;33:1078-81.

6. Bitter K, Kielbassa AM. Post-endodontic restorations with adhesively luted fiber-reinforced composite post systems: a review. Am J Dent 2007; 20:353-60.

7. Cagidiaco MC, Goracci C, Garcia-Godoy F, Ferrari M. Clinical studies of fibre posts: a literature review. Int $\mathbf{J}$ Prosthodont 2008; 21:328-36.

8. DeSantis R, Prisco D, Apicella A, Ambrosio L, Rengo $S$,Nicolais L. Carbon fiber post adhesion to resin luting cement in the restoration of endodontically treated teeth. $\mathrm{J}$ Mater Sci Mater Med 2000; 11: 201-6. 
9. Roberts HW, Leonard DL, Vandewalle KS, Cohen ME, Charlton DG. The effect of a translucent post on resin composite depth of cure. Dent Mater 2004; 20:617-22.

10. Ferrari M, Cagidiaco MC, Grandini S, De Sanctis M, Goracci C. Post placement affects survival of endodontically treated premolars. J Dent Res 2007; 86:729-34.

11. Cagidiaco MC, Radovic 1, Simonetti M, Tay F, Ferrari M. Clinical performance of fiber post restorations in endodontically treated teeth: 2-year results. Int J Prosthodont 2007; 20:293-8.

12. Grandini S, Goracci C, Tay FR, Grandini R, Ferrari M. Clinical evaluation of the use of fiber posts and direct resin restorations for endodontically treated teeth. Int $\mathbf{J}$ Prosthodont 2005; 18:399-404.

13. Monticelli F, Grandini S, Goracci C, Ferrari M. Clinical behavior of translucent-fiber posts: a 2-year prospective study. Int J Prosthodont 2003; 16:593-6.

14. Naumann M, Blankenstein F, Kiessling S, Dietrich T. Risk factors for failure of glass fiber-reinforced composite post restorations: a prospective observational clinical study. Eur J Oral Sci 2005; 113:519-24.

15. Naumann M, Sterzenbac G, Alexandra F, Dietrich T. Randomized controlled clinical pilot trial of titanium vs. glass fiber prefabricated posts: preliminary results after up to 3 years. Int J Prosthodont 2007; 20:499-503.

16. 17.Monticelli F. Osorio R. Sadek FT, Radovic 1, Foledano M, Ferrari M. Surface treatments for improving bond strength to prefabricated fiber posts: a literature review. Oper Dent 2008; 33: 546-55.

17. Bitter K, Kielbassa AM. Post-endodontic restorations with adhesively luted fiber-reinforced composite post systems: a review. Am J Dent 2007;20:353-60.

18. Choi Y, Pae A, Park EJ, Wright RF. The effect of surface treatment of Fiber-reinforced posts on adhesion of a resinbased luting agent. J Prosthet Dent 2010; 103: 362-8.

19. Sahafi A, Peutzfeldt A, Asmussen E, Gotfredsen K. Retention and failure morphology of prefabricated posts. Int J Prosthod 2004; 17:307-12.

20. Valandro LF, Yoshiga S, de Melo RM, Galhano GA, Mallmann A, Marinho CP, et al. Microtensile bond strength between a quartz fiber post and a resin cement: effect of post surface conditioning. J Adhes Dent 2006; 8:105-11.

21. Chu P, Chen J, Wang L, Huang N. Plasma surface modification of biomaterials. Mater ScienEng Rep 2002; 36:143-6.
22. Cekic-Nagas I, Ergun G. Effect of different light curing on mechanical and physical properties of resin-cements polymerized through ceramic discs. J Appl Oral Sci 2011; 19:403-12.

23. Shadman N, Atai M, Ghavam M, Kermanshah FI, Ebrahimi SF. Parameters affecting degree of conversion of dual-cure resin cements in the root canal: FTIR analysis. J Can Dent Assoc 2012; 78:c53.

24. Martinez-lnsua A, Da Silva Dominguez L, Rivera FG, Santana-Penfn UA. Differences in bonding to acid-etched or Er: YAG-laser-treated enamel and dentin surfaces. J Prosthet Dent 2000; 84:280-8.

25. Subramaniam P, Pandey A. Effect of erbium, chromium: Yttrium, scandium, gallium, garnet laser and casein phosphopeptide-amorphous calcium phosphate on surface micro-hardness of primary tooth enamel. Eur J Dent 2014; 8: 402-6.

26. Alavi S, Birang R, Hajizadeh F. Shear bond strength of orthodontic brackets after acid-etched and erbium-doped yttrium aluminum garnet laser-etched. Dent J (Isfahan) 2014; 11:321-6.

27. Goracci C, Corciolani G, Vichi A, Ferrari M. Fighttransmitting ability of marketed liber posts. J Dent Res 2008;87:1 122-6.

28. dos Santos GB, Alto RV, Filho HR, da Silva EM, Fellows CE. Fight transmission on dental resin composites. Dent Mater 2008; 24:571-6.

29. Radovic I, Corciolani G, Magni E, Krstanovic G. Pavlovic V, Vulicevic ZR . Light transmission through fiber post: The effect on adhesion, elastic modulus and hardness of dual-cure resin cement. Dent Mater. 2009; 25:837-44.

30. Ferrari M, Breschi L, Grandini S. Fiber Posts and Fndodontically Treated Teeth: A Compendium of Scientific and Clinical Perspectives of the Cement. 1st ed. Singapore: Modem Dentistry Media; 2008.

31. Cekic-Nagas I, Sukuroglu E, Canay S. Does the surface treatment affect the bond strength of various fibre-post systems to resin-core materials? J Dent 2011; 39:1719.

32. Samimi P, Mortazavi V, Salamat F. Effects of heat treating silane and different etching techniques on glass fiber post push-out bond strength. Oper Dent 2014; 39:E217-24.

33. Hsu FH, Wang NF, Tsai YZ, Chien MH, Houng MP. Improvement of short-circuit current density in $\mathrm{p}-\mathrm{o}$ : $\mathrm{Li} / \mathrm{n}$ si heterojunction solar cells by wet chemical etching. $\mathrm{J}$ Nanomater 2014; 2014:1-7. 
34. Harada T, Murotani H, Matumoto S, Honda H. Influence of substrate surface roughness on light scattering of Ti02 optical thin films. Chin Opt Lett 2013; 11:1-4.

35. Hoshing UA, Patil S, Medha A, Bandekar SD. Comparison of shear bond strength of composite resin to enamel surface with laser etching versus acid etching: An in vitro evaluation. J Conserv Dent 2014; 17: 320-4.

36. Akova T, Yoldas O, Toroglu MS, Uysal H. Porcelain surface treatment by laser for bracket-porcelain bonding. Am J Orthod Dentofacial Orthop 2005; 128:630-7.

37. Sipahi C, Piskin B,Akin GE, Bektas OO, Akin H. Adhesion between glass fiber posts and resin cement: Evaluation of bond strength after various pre-treatments. Acta Odontol Scand 2014;72:509-15.

38. Grandini S, Goracci C, MonticelliF, Tay FR, Ferrari M. Fatigue resistance and structural characteristics of fiber posts: three-point bending test and SEM evaluation. Dent Mater 2005; 21.

39. Akkayan B, Gulmez T. Resistance to fracture of endodontically treated teeth restored with different post systems. J Prosthet Dent 2002; 87:431-7.

40. NewmanMP, Yaman P, Dennison J, Rafter M, Billy E. Fracture resistance of endodontically treated teeth restored with composite posts. J Prosthet Dent 2003; 89:360-7.

41. LassilaLV, Tanner J, Fe Bell AM, Narva K, Vallittu PK. Flexural properties of fiber reinforced root canal posts. Dent Mater 2004; 20:29-36.

42. Grandini S, Goracci C, MonticelliF, TayFR, Ferrari M. Fatigue resistance and structural characteristics of fiber posts: three-point bending test and SEM evaluation. Dent Mater 2005; 21:75-82.

43. Tezvergil A, LassilaLV, Vallittu PK. The effect of fiber orientation on the thermal expansion coefficients of fiberreinforced composites. Dent Mater 2003; 19:471-7.

44. Gu W. Interfacial adhesion evaluation of uniaxialfiberreinforced-polymer composites by vibration damping of cantilever beam. PhD Thesis. Virginia Polytechnic Institute and State University; 1997. p. 11-3. 